\title{
An Empirical Study on the Predictors of the Perceived Quality of Learning at Institutions of Higher Education: 2D Model Approach
}

\author{
https://doi.org/10.3991/ijet.v14i15.10608 \\ Mmatlou Matlakala, Norman Chiliya \\ University of the Witwatersrand, Johannesburg, South Africa \\ Tinashe Chuchu, $\left.{ }^{(}\right)$, Tinashe Ndoro \\ University of Pretoria, Pretria, South AFrica \\ tinashe.chuchu@up.ac.za
}

\begin{abstract}
The purpose of the present study was to conduct an empirical investigation into the predictors of the perceived quality of learning at institutions of higher education from the student's perspective. The research was based on a conceptual model consisting of six proposed hypotheses. A quantitative study that utilised the survey methodology was adopted as it was imperative to obtain objective findings that would later be used for statistical purposes. In terms of selection of suitable participants for the study, non-probability sampling, a form of convenience sampling was adopted. Perceptions of students regarding the quality of education were tested empirically. The $2 \mathrm{D}$ Model approach was adopted to investigate this phenomenon. Data was collected from a total of 300 students from a selected university in South Africa. To analyse the data SPSS 24 and AMOS 24 were utilised for descriptive statistics and hypotheses testing respectively. A university's reputation and the geographic region a student originated from were observed as having the greatest influence on those students' perception of quality of education that a higher education institution provided.
\end{abstract}

Keywords-Learning, quality education, students, perceptions, 2 D Model

\section{Introduction}

Quality of education has been receiving attention in academia and this has been associated with the growing use information communication technologies in higher educational institutions [1]. [2] states that "education institutions try hard to draw attention of the public so that they can attract and enrol as many students as possible and that there is a plethora of advertisements and other types of marketing promotions during admission period to depict quality of education program offered by different organizations". There are different types of performance rankings of higher education institutions which are mainly focused on student customers [3]. Development of quality perception is required for drawing attention, delivery of program and satisfying customers' needs according to marketing perspective [2]. Quality perception is 
subjective judgment of customers rather than objective reality [4]. [2] observed that the antecedents of quality perceptions in customers as students but stakeholders' perception of quality of education programs has not been empirically measured so far. The present study focused on potential antecedents of the perceived quality of education from a student's perspective.

Perceived quality of learning has become a relevant topic and other scholars have looked at it from a similar perspective as to that of this research. For instance [13], examined the perceived quality of education from the students' perspective as well as from educational institution's external reputation. Furthermore, [13] specifically analysed the level of satisfaction of existing master's students with both academic and non-academic factors so as to establish indicators of quality at the higher education institutions. The present study in question also discussed institutional reputation in relation to the perceived quality of education. In addition [13] also emphasised that higher education institutions such as universities should remember to bring together high quality education, research and development of the nations that host those higher education institutions while attracting the top international students and academics. Similar to the study by [13] this research highlighted the effect that perceived quality of education also has on international students' perceptions of the quality of education provided by higher education institution of learning.

The present study considered the geographic region that the learners where coming from. This study then investigated whether the geographic region of learners' influenced their perceptions of quality of education that an institution provided. Some European studies such as [15], have also investigated quality of education at higher education. [15] examined how increased attention to responsibility from the instructors and in European institutions of higher education, supported by performance measurement and assessment, had the quality of teaching as perceived by academics. However, the present study looks at perceived quality from the student's perspective and not from the academics perspective as was done by [15]. The predictors which formed part of the conceptual model comprised of "cost", influence of family and friends, geographic area, promotional activities, university reputation, future employment prospects and academic programmes. The outcome of the conceptual model was the perceived quality of education.

\subsection{Statement of the problem}

This study aims to assess the factors that influence university students perceive the quality of education at university and the consequent decision to enrol at the university. Prior research on quality and innovation has been conducted [5], [6] and [7], but did not look at how innovation influences students' willingness to enrol for further studies. This research goes further by investigating the potential predictors of perceived of quality of education from the students' perspective when future employment prospects are also considered a challenge for them. None of the abovementioned research had used the $2 \mathrm{D}$ Model approach to investigate student's perception of quality of education. 


\section{University 2 D Model}

Students' educational mobility, traditionally limited within domestic education, now expands its volumes and ranges of motion international [8]. The 2-D model illustrates the answer to the question of why students choose to study abroad. As evident in this study a considerable number of students were from outside South Africa. The two factors defined by this model are the driving force factor and directional factor. The first $\mathrm{D}$, the driving force factor, refers to the internal, domestic, and home components that initially drive students' outward mobility for foreign higher education [8]. The outward mobility is often driven by various personal and situational reasons and each individual would have different sets of driving force factors [8]. Among these, this study focuses on the dissatisfaction with domestic higher education perceived by Korean students, which has been a serious issue in Korean higher education

The second D, the directional factor, refers to the students' perceptions of images and expectations for foreign higher education, which may influence the directional decisions on the destination country [8]. This model was used to aid in comprehension of how university students would perceive quality of education an institution provided. Constructs of the Research Model

Cost of tuition has been considered a factor that would discourage international students from attending higher education institutions [15], [16]. However a study conducted within a South African context by [14], established that introducing actually had a positive impact on South Africa is it was the key drivers of the economy due to the considerable to amount of revenue it generated for the nation's economy. Cost was measured against perceived quality of education so as it to establish the kind of impact it had on student's perception of education quality an institution provided. The study also looked at whether the influence of family and friends influenced the likelihood of a prospective student to select a higher education institution for further studies or not? As discussed previously the geographic region that a student originated from also played an important role in this study as it was necessary to establish whether students' background would influence their perception of quality that a higher education institution provided. This study looked at the link between perceived quality of education an institution provided and the institution's reputation. This study echoes that of [17], who investigated university reputation and relational quality in the context of student-university relationships. Lastly, future employment prospects and academic programmes offered by an institution were measured against the institution's perceived quality of education. This was to assess whether academic course and the prospect of finding a job affected students perception of educational quality provided by a university.

\subsection{Research model and hypotheses statements}

A research model was conceptualized with hypothesised relationships between constructs were developed to be explored further. In the conceptualised research model, the cost of education, influence of family/friends, future employment prospects, university reputation, promotional activities carried out by the university and geo- 
graphical area are the independent variables. Perceived quality of education is the dependent variable. Figure 1 below represents the proposed conceptual model for the study.

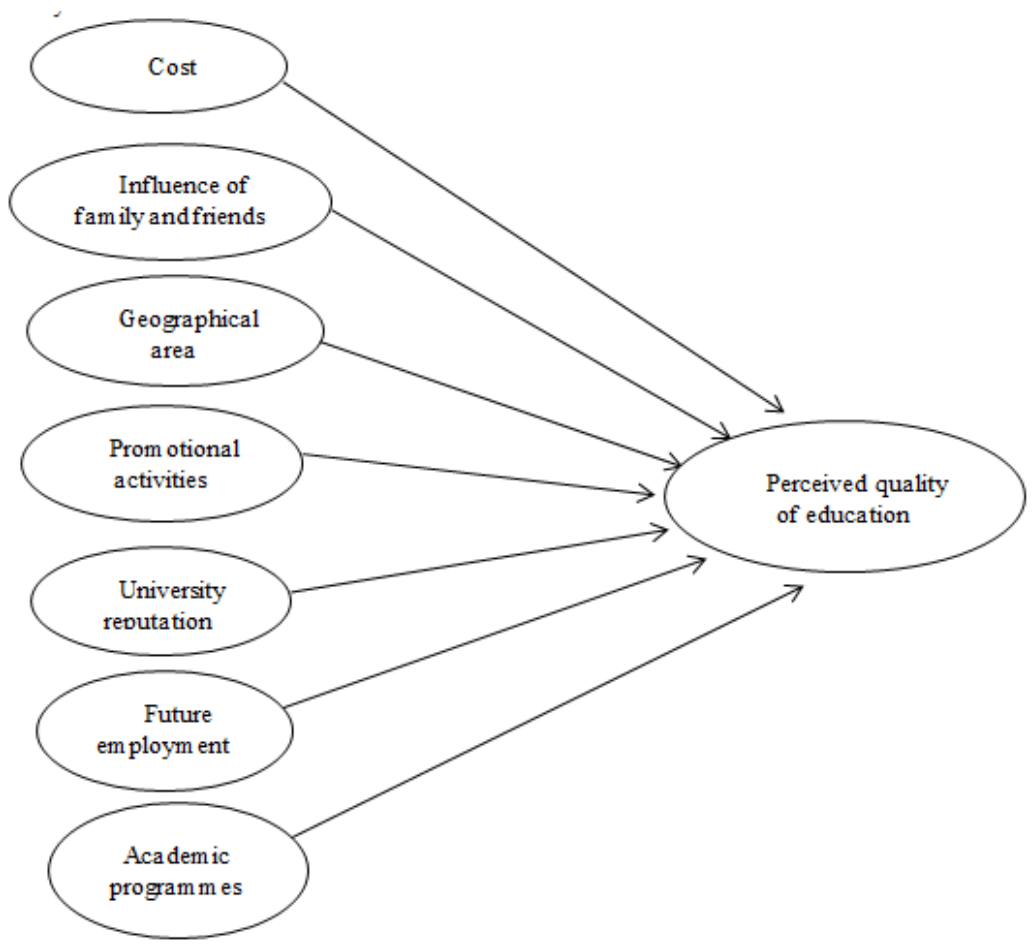

Fig. 1. Conceptual Model

Based on the conceptual model in Figure 1 above, the following hypotheses are developed.

Hypothesis 1: The cost of education has a positive influence on perceived quality

Higher education marketers are faced with a complicated question of whether high prices of education is seen as a sign of higher quality, or whether higher prices only discourage students from attending a particular university? Therefore, it would stand to reason that colleges and universities which were perceived as being higher in quality could charge a higher level of tuition [9]. Based on this previous study, the assumption is that the cost of education is directly proportional to the quality of education.

Hypothesis 2: The influence of family/ friends has a positive influence on the perceived quality of education

Some students choose a university based on referrals by family members and friends. The fact that their loved ones obtained degrees from a particular university might lead to their assumption that the university offers high quality education. 
Hypothesis 3: promotional activities executed by the university have a positive influence on perceived quality of education

Hypothesis 4: the good reputation of the university has a positive influence on the perceived quality of education at a university

[9] states that reputation ranking is a perception of quality. A high quality reputation would tend to entice students to apply to the school [9].

Hypothesis 5: future employment prospects have a positive influence on perceived quality of education students' choice to study at a university

Hypothesis 6: the area where a university is situated impacts positively on the quality of education.

\section{$3 \quad$ Research Method}

The study adopted a positivist approach where it was quantitative in nature. The survey methodology was used and involved distributing questionnaires to willing participants at a selected university in South Africa. A total of 300 responses were obtained from data collection. Due to difficulty of ensuring that all participants would agree to participate, non-probability sampling, a form of convenience sampling was utilised in selection of willing participants. A considerable number of the students that participated in the study were international students. To this end the $2 \mathrm{D}$ model became relevant for the research and was utilised to understand why students would choose to study abroad. The participants were current students of the institution and the questionnaire was designed to establish their likelihood of continuing studies at that institution. To analyse collected data was captured, cleaned and exported to SPSS 24 for descriptive statistics and reliability tests. Furthermore, the data was analysed in AMOS 24 in order to test the study's proposed hypotheses. Advanced statistics involved structural equation modelling where it was conducted following a two step procedure. The first being confirmatory factory analysis which was to ensure that scales adapted for the study were still valid and the second stage being hypothesis testing to examine the outcomes of the proposed relationships of the conceptual model.

\section{$4 \quad$ Results}

Table 1 below presents the demographic profile of the respondents. A selected university in Johannesburg, South Africa was used as the sample frame, and only registered students were surveyed. The profile indicates that the percentage of males to females is higher at $55 \% .43 \%$ were females and $2 \%$ preferred not to indicate their gender. The dominating age group for this study were 27 -year olds and older, and this represents $45.3 \%$ of the sample. The age group with the least number of respondents was 23-26 which represents $27.1 \%$ of the sample. The age group 18-23 represents $33 \%$ of the population. 
Table 1. Sample Demographic Profile

\begin{tabular}{|c|c|c|}
\hline Gender & Frequency & Percentage \\
\hline Male & 165 & $55.0 \%$ \\
\hline Female & 129 & $43.0 \%$ \\
\hline Prefer Not to Say & 6 & $2.0 \%$ \\
\hline Total & 300 & $100 \%$ \\
\hline Age & Frequency & Percentage \\
\hline $18-22$ & 99 & $33 \%$ \\
\hline $23-26$ & 69 & $21.7 \%$ \\
\hline $27>$ & 132 & $45.3 \%$ \\
\hline Total & 300 & $100 \%$ \\
\hline Level of Study & Frequency & Percentage \\
\hline Undergraduate & 124 & $41.3 \%$ \\
\hline Honours & 20 & $6.7 \%$ \\
\hline Masters & 88 & $29.3 \%$ \\
\hline $\mathrm{PhD}$ & 68 & $22.7 \%$ \\
\hline Total & 300 & $100 \%$ \\
\hline Region of Origin & Frequency & Percentage \\
\hline Africa & 238 & $79.3 \%$ \\
\hline Europe & 27 & $9.0 \%$ \\
\hline Asia & 15 & $5.0 \%$ \\
\hline North America & 8 & $2.7 \%$ \\
\hline South America & 6 & $2.0 \%$ \\
\hline Australia & 6 & $2.0 \%$ \\
\hline Total & 300 & $100 \%$ \\
\hline Course Registered & Frequency & Percentage \\
\hline Business Science & 63 & $21.0 \%$ \\
\hline Accounting & 5 & $1.7 \%$ \\
\hline Law & 29 & $9.7 \%$ \\
\hline Math \& Science & 35 & $11.7 \%$ \\
\hline Engineering & 61 & $20.3 \%$ \\
\hline Medicine & 45 & $15.0 \%$ \\
\hline Other & 62 & $20.7 \%$ \\
\hline Total & 300 & $100 \%$ \\
\hline
\end{tabular}

The table presents sample demographic profile for the study. In terms of gender males had a larger representation as compared to female participants. This was indicated by the males accounting for $55 \%$ of the sample and female participants accounting for $43 \%$ of the total sample. However, it could be observed that $2 \%$ of all participants refused to disclose their gender identity. Ages of participants were also taken into consideration. Students aged from 18 to 22 were 99 participants and accounted for $33 \%$ of the sample while students aged 23-26 accounted for almost $22 \%$ of the sample and lastly students above 27 years were represented by $45 \%$ of all the participants.

The level of study of the students was also taken into consideration for this study. Undergraduate students accounted for $41 \%$ of the total sample as indicated by 124 out-off a total of 300 students. This was also the most represented group of students in terms of study level which probably suggested that the research topic resonated most- 
ly with this study level. Furthermore, honours students represent at lest $7 \%$ of the sample while masters students represented $29 \%$ of the sample. PhD students were represented by at least $22 \%$ of the sample.

Students from Africa had the high representation as the accounted for $79 \%$ of the total sample. This could possibly be explained by the fact that the institution of higher education used for this study was based in Africa. The least represented regions of origin were South America and Australia which only accounted for 2\% each and 4\% collectively of the total sample. Students registered for various courses with business science being the most represented at $21 \%$ while accounting science had the lowest representation at almost $2 \%$.

\subsection{Model fit checks}

After path modeling, the following results were obtained.

Chi-square $(\chi 2 / \mathrm{df})=1.751$, Goodness of Fit Index $(\mathrm{GFI})=0.902$, Comparitive Fit Index $(\mathrm{CFI})=0.939$, Tucker Lewis Index $(\mathrm{TLI})=0.907$, Incremental Fit Index $(\mathrm{IFI})=$ 0.942 , Relative Fit Index $(\mathrm{RFI})=0.807$, Norm Fit Index $(\mathrm{NFI})=0.874$, and Random Measure of Standard Error Approximation (RMSEA) $=0.05$. The model fit results confirmed that all the recommended thresholds were met. This allowed for further analysis to be conducted. Hypothesis testing was then carried out and results are presented in table 3 . The main analysis conducted was the structural equation modeling technique which involved a two-step process beginning with confirmatory factor analysis which produced the values for model fit checks and the hypotheses testing with indicated levels of significance through the p-values. For reliability assessment the Cronbach's alpha was calculated and as observed in table 3 all the values were above the recommended threshold of 0.6 Perceived quality (PQ), Cost (C), Influence of family and friends (IF), Geographic area (GA), Promotional activities (PA), University reputation (UR) and Future employment prospects (FE) are all presented in the following table, table 2 .

Table 2. Accuracy analysis statistics

\begin{tabular}{|c|c|c|c|c|c|c|c|}
\hline \multirow{2}{*}{\multicolumn{2}{|c|}{$\begin{array}{c}\text { Research Con- } \\
\text { struct }\end{array}$}} & \multicolumn{2}{|c|}{ Descriptive Statistics } & \multicolumn{2}{|c|}{ Cronbach's Test } & \multirow{2}{*}{ C.R. Value } & \multirow{2}{*}{ Factor Loading } \\
\hline & & Mean Value & $S D$ & Item-total & A value & & \\
\hline \multirow[t]{3}{*}{ PQ } & PQ1 & 4.313 & 0.937 & 0.525 & \multirow{3}{*}{0.711} & \multirow{3}{*}{0.702} & 0.590 \\
\hline & PQ2 & 4.437 & 0.708 & 0.557 & & & 0.707 \\
\hline & PQ3 & 3.673 & 0.964 & 0.539 & & & 0.690 \\
\hline \multirow[t]{3}{*}{$\mathrm{C}$} & $\mathrm{C} 1$ & 2.343 & 1.031 & 0.561 & \multirow{3}{*}{0.628} & \multirow{3}{*}{0.623} & 0.764 \\
\hline & $\mathrm{C} 2$ & 2.303 & 1.014 & 0.582 & & & 0.842 \\
\hline & $\mathrm{C} 3$ & 2.567 & 1.155 & 0.327 & & & 0.091 \\
\hline \multirow[t]{5}{*}{ IF } & IF1 & 2010 & 1305 & 0.409 & \multirow{5}{*}{0.681} & \multirow{5}{*}{0.615} & 0.473 \\
\hline & IF2 & 3003 & 1340 & 0.500 & & & 0.678 \\
\hline & IF3 & 2970 & 1415 & 0.545 & & & 0.585 \\
\hline & IF4 & 3133 & 1462 & 0.460 & & & 0.616 \\
\hline & IF5 & 2.063 & 1282 & 0.270 & & & 0.046 \\
\hline \multirow[t]{2}{*}{ GA } & GA1 & 2.317 & 0.980 & 0.0 .297 & \multirow{2}{*}{0.656} & \multirow{2}{*}{0.608} & 0.457 \\
\hline & GA2 & 2.927 & 1.426 & 0.260 & & & 0.067 \\
\hline
\end{tabular}




\begin{tabular}{|c|c|c|c|c|c|c|c|}
\hline & GA3 & 3.987 & 1.315 & 0.347 & & & 0.236 \\
\hline & GA4 & 2.873 & 1.340 & 0.527 & & & 0.229 \\
\hline & GA5 & 2.920 & 1.288 & 0.416 & & & 0.252 \\
\hline & GA6 & 2.613 & 1.135 & 0.194 & & & 0.261 \\
\hline & GA7 & 3.300 & 1.126 & 0.340 & & & 0.627 \\
\hline & GA8 & 3.620 & 1.107 & 0.452 & & & 0.974 \\
\hline \multirow[t]{2}{*}{$\mathrm{P}$} & P1 & 3753 & 0.967 & 0.489 & \multirow{2}{*}{0.656} & \multirow{2}{*}{0.542} & 0.693 \\
\hline & P2 & 3070 & 0.942 & 0.489 & & & 0.701 \\
\hline \multirow[t]{3}{*}{ UR } & UR1 & 4080 & 0.904 & 0.571 & \multirow{3}{*}{0.754} & \multirow{3}{*}{0.766} & 0.768 \\
\hline & UR2 & 4133 & 0.786 & 0.640 & & & 0.768 \\
\hline & UR3 & 3870 & 0.903 & 0.549 & & & 0.657 \\
\hline \multirow[t]{5}{*}{$\mathrm{FE}$} & FE1 & 3937 & 0.903 & 0.715 & \multirow{5}{*}{844} & \multirow{5}{*}{901} & 0.867 \\
\hline & FE2 & 4033 & 0.880 & 0.772 & & & 0.790 \\
\hline & FE3 & 3863 & 0.913 & 0.648 & & & 0.754 \\
\hline & FE4 & 4020 & 0.907 & 0.769 & & & 0.799 \\
\hline & FE5 & 3953 & 0.924 & 0.760 & & & 0.802 \\
\hline
\end{tabular}

Key: Perceived quality (PQ), Cost (C), Influence of family and friends (IF), Geographic area (GA), Promotional activities (PA), University reputation (UR), Standard deviation (SD), Composite reliability (CR), Future employment prospects (FE)

As observed in the accuracy analysis statistics table (table 2), mean values ranged from 3 to 4 therefore it could be assumed that the respondents were fairly spread. The standard deviation values were between -2 to +2 thereby also revealing fair distribution of respondents. The average variance extracted values were generally above the acceptable threshold of 0.5 as recommended by [10]. As for reliability the Cronbach's alpha values were above 0.6 as recommended by literature [11]. The composite reliability values were above 0.7 , meeting the threshold suggested [12] respectively.

Composite reliabilities (CR) for each construct were also generated using the following formula

\section{$\mathbf{C R} \boldsymbol{\eta}=(\Sigma \lambda \mathrm{yi}) 2 /[(\Sigma \lambda \mathrm{yi}) 2+(\Sigma \varepsilon i)]$}

Where

$\mathrm{CR} \eta=$ Composite reliability, $(\Sigma \lambda$ yi) $2=$ Square of the summation of the factor loadings; $(\Sigma \varepsilon i)=$ Summation of error variances.

The following table presents the results of hypothesis testing. "Perceived quality" was tested against "Cost", "Influence of family and friends", "Geographic area", "Promotional activities", "University reputation" and "Future employment prospects". In addition the table also provides $\mathrm{p}$ values for each hypothesis are provided. The level of significance for each hypothesis are presented and measured at $\mathrm{p}<0.01$ as well as at $\mathrm{p}<0.05$. 
Table 3. Results of Structural Equation Model Analysis

\begin{tabular}{|l|c|c|l|}
\hline \multicolumn{2}{|c|}{ Hypotheses Relationship } & P-value & \multicolumn{1}{c|}{ Outcome } \\
\hline PQ<---C & H1 & 0.031 & Supported and significant at $\mathrm{p}<0.05$ \\
\hline $\mathbf{P Q}<---$ IF & H2 & 0.086 & Not supported and not significant \\
\hline PQ<---FE & H3 & $* * *$ & Supported and significant at $\mathrm{p}<0.01$ \\
\hline $\mathbf{P Q}<---$ UR & H4 & $* * *$ & Supported and significant at $\mathrm{p}<0.01$ \\
\hline PQ<---P & H5 & 0.211 & Not supported and not significant \\
\hline PQ<---GA & H6 & $* * *$ & Supported and significant at $\mathrm{p}<0.01$ \\
\hline
\end{tabular}

KEY: Perceived quality (PQ), Cost (C), Influence of family and friends (IF), Geographic area (GA), Promotional activities (PA), University reputation (UR), Standard deviation (SD), Composite reliability (CR), Future employment prospects (FE)

Levels of significance: $\mathrm{p}<0.01$ and $\mathrm{p}<0.05$

\subsection{Discussion of hypotheses results}

As observed in the findings above $\mathrm{H} 1$ (perceived quality of education and cost) were directly related and this implied that the greater the perceived quality of education the higher the cost of education would be at the university. This relationship was both significant and supported at $p<0.05$ with a $p$ value of 0.0031 . H1 (perceived quality of education and influence of friends and family) was both supported and significant. This suggested that the was not correlation between the influence that friends and family and the student's perception of the quality of education. H3 (Future employment prospects and perceived quality of education) was found to be significant at $p<0.01$ as indicated by the $(* * *)$. This suggested that students perceived a university with high quality of education to provide them great future employment prospects. $\mathrm{H} 4$ (University reputation and perceived quality of education) was found to be supported and significant at $\mathrm{p}<0.01$ denoted by the $(* * *)$. This suggested that a university with a highly regarded reputation was viewed as a higher education institution with a higher perceived quality of education. H5 (Promotional activities and perceived quality of education) was viewed to have no relationship. This relationship was both not supported and not significant implying that the promotional activities conducted by or for and educational institution had not impact of the perception of quality education at that institution. H6 (Geographic area and perceived quality of education) supported and significant at $\mathrm{p}<0.01$ denoted by the $(* * *)$. This suggested that the geographic area from with a student came from had a great influence on how that student perceived the level and quality of education a university provided.

\section{Conclusion}

It could be concluded that based on findings of the research a universities reputation had great influence of a prospective student's perception of the quality of education that the educational institution provided. In addition, it was also observed that the amount of promotion done in support of an educational institution had no impact whatsoever on how prospective students perceived the quality of education the university provided. 


\section{Recommendations and Suggestions for Future Research}

Based on findings of the study it be suggested that university invest less in money that is aimed at promotion of the institution as this was found to have no impact on the prospective student's perception of the quality of education that the student provided. It could be suggested that future research be conducted on a larger scale and not focus on only one institution as this could have produced sample bias. Another recommendation is that institutions of higher education could focus investing in and analysing big data associated with predicting students' potential to enroll with an education of higher learning.

\section{$7 \quad$ References}

[1] Buabeng-Andoh, Charles. "Factors influencing teachersâ adoption and integration of information and communication technology into teaching: A review of the literature." International Journal of Education and Development using ICT8.1 (2012).

[2] Shrestha, B. K. (2013). Public perception of the quality of academic education program. Journal of education and research, 3(1), 52-64.

[3] Dill, D. D., \& Soo, M. (2005). Academic quality, league tables, and public policy: A crossnational analysis of university ranking systems. Higher education, 49(4), 495-533. https://doi.org/10.1007/s10734-004-1746-8

[4] Schiffman, L. G., Kanuk, L. L., Kumar, S. R., \& Wisenblit, J. (2010). Consumer decision making and beyond. Consumer behavior, 424-465.

[5] Liu, K. (2017). Design and Application of an Online English Self-learning Platform. International Journal of Emerging Technologies in Learning (iJET), 12(08), 4-13. https://doi.org/10.3991/ijet.v12i08.7133

[6] Neira, E. A. S., Salinas, J., \& De Benito, B. (2017). Emerging Technologies (ETs) in Education: A Systematic Review of the Literature Published between 2006 and 2016. International Journal of Emerging Technologies in Learning (IJET), 12(05), 128-149. https://doi.org/10.3991/ijet.v12i05.6939

[7] Solihati, N., \& Mulyono, H. (2017). A Hybrid classroom instruction in second language teacher education (SLTE): A critical reflection of teacher educators. International Journal of Emerging Technologies in Learning (iJET), 12(05), 169-180. https://doi.org/10. 3991/ijet.v12i05.6989

[8] Park, E. L., 2009. Analysis of Korean Students' International Mobility by 2-D Model: Driving Force Factor and Directional Factor. Higher Education, 57(6), pp. 741-755. https://doi.org/10.1007/s10734-008-9173-x

[9] Wright, S. (2015). Medical school personal statements: a measure of motivation or proxy for cultural privilege? Advances in Health Sciences Education, 20(3), 627-643. https://doi.org/10.1007/s10459-014-9550-4

[10] Fraering, M., \& Minor, M. S. (2006). Sense of community: An exploratory study of US consumers of financial services. International Journal of Bank Marketing, 24(5), 284-306. https://doi.org/10.1108/02652320610681738

[11] Dusick, D., (2011). Writing the methodology section. Retrieved from: http://www.bolded.com/ch3.htm. Accessed [12/02/2017]

[12] Hair, J.F., Anderson, R.E, Tatham, R.L. and Black, W.C. (2006) Multivariate data analysis, 6th edition, London: Prentice-Hall. 
[13] Jogunola, O., \& Varis, K. (2019). How to Measure and Manage Perceived Quality of Higher Education by International Degree Students at Two Case Universities in Finland. Journal of Management, 20(1), 59-74. https://doi.org/10.33423/jmpp.v20i1.1329

[14] Pouris, A., \& Inglesi-Lotz, R. (2014). The contribution of higher education institutions to the South African economy. South African Journal of Science, 110(3-4), 01-07. https://doi.org/10.1590/sajs.2014/a0059

[15] Teelken, C. (2018). Teaching assessment and perceived quality of teaching: a longitudinal study among academics in three European countries. European Journal of Higher Education, 8(4), 382-399. https://doi.org/10.1080/21568235.2018.1490661

[16] Usher, H (2016). Lesson from Scandinavia on the Value of Tuition Fees. Higher Education Associates. Retrieved from http://higheredstrategy.com/lessons-from-scandinavia-on-thevalue-of-tuition-fees/ (Accessed 2019/04/05). https://doi.org/10.21125/iceri.2018.0635

[17] Yang, S. U., Alessandri, S. W., \& Kinsey, D. F. (2008). An integrative analysis of reputation and relational quality: A study of university-student relationships. Journal of Marketing for Higher Education, 18(2), 145-170. https://doi.org/10.1080/08841240802487353

\section{Authors}

Mmatlou Matlakala is a student in the Marketing Division of the School of Economic and Business Sciences and a faculty of commerce, Law and Management at the University of the Witwatersrand, Johannesburg, South Africa.

Dr Norman Chiliya Ph.D. is a senior lecturer and the head of the Marketing Division in the School of Economic and Business Sciences and faculty of commerce, Law \& Management, at the University of the Witwatersrand, Johannesburg, South Africa.

Dr Tinashe Chuchu Ph.D. is a senior lecturer in the Department of Marketing Management in the Faculty of Economic and Management Sciences at the University of Pretoria, South Africa.

Dr Tinashe Ndoro Ph.D. is a senior lecturer in the Department of Marketing Management in the Faculty of Economic and Management Sciences at the University of Pretoria, South Africa.

Article submitted 2019-04-05. Resubmitted 2019-06-06. Final acceptance 2019-06-08. Final version published as submitted by the authors. 